\title{
Comparative Study of Rosuvastatin as Monotherapy Versus Rosuvastatin with Ramipril in Dyslipidemia and Their Effects on Atherosclerosis
}

\author{
Kumar Raj, ${ }^{1 *}$, Garg Ravinder ${ }^{2}$, Aggarwal Simmi $^{3}$, Kohli Kamlesh ${ }^{1}$, Misra Gansham ${ }^{4}$ \\ ${ }^{1}$ Department of Pharmacology, Guru Gobind Singh Medical College and Hospital (Baba Farid University of Heath Sciences), Faridkot \\ -151203, INDIA \\ ${ }^{2}$ Department of Medicine, Guru Gobind Singh Medical College and Hospital (Baba Farid University of Heath Sciences), Faridkot - \\ 151203, INDIA \\ ${ }^{3}$ Department of Radiodiagnosis, Guru Gobind Singh Medical College and Hospital (Baba Farid University of Heath Sciences), Faridkot \\ -151203 , INDIA \\ ${ }^{4}$ Department of Social and Preventive Medicine, Guru Gobind Singh Medical College and Hospital (Baba Farid University of Heath \\ Sciences), Faridkot -151203, INDIA \\ * Corresponding author: anurajkumar76@gmail.com
}

Received May 11, 2014; Revised June 17, 2014; Accepted June 17, 2014

\begin{abstract}
Objective: To evaluate the effect of Rosuvastatin as monotherapy versus combination therapy of Rosuvastatin with Ramipril on the Intimo-Media Thickness (IMT) of the carotid arteries in patients of dyslipidemia. Background: Statins have shown to improve the lipid profile in dyslipidemic patients. These have anti-oxidative and anti-inflammatory actions. The statins may have also antiatherosclerotic action. Angiotensin converting enzyme (ACE) inhibitors have shown to prevent the development of atherosclerosis in animal models. This antiatherosclerotic effects of ACE inhibitors is due to their multitask actions viz. ACE inhibition, antiproliferative action as well as inhibitory to the smooth muscle cell accumulation at the site of atherosclerotic lesion. Method: 88 patients of newly diagnosed dyslipidemia, aged 30-70 years, were randomized into two groups. Group I, was allocated Rosuvastatin (as monotherapy) and Group II, Rosuvastatin with Ramipril (Combination therapy). Patients were assessed at baseline, 6 weeks and 12 weeks for carotid arteries for IMT and plaque size by B-mode ultrasound, and other parameters were also assessed. Results: In group I and group II, mean percentage change in TC, LDL, TG and HDL was highly significant $(\mathrm{p}<0.001)$ in both the groups while no significant change was seen between the groups at 12 weeks. Mean percentage change in mean IMT and plaque size were $+0.01224 \%(\mathrm{p}>0.05)$ versus $0.0704 \%(\mathrm{p}>0.05)$ and $+0.006 \%(\mathrm{p}>0.05)$ versus $-4.554 \%(\mathrm{p}>0.05)$ respectively in group I and group II at 12 weeks while these changes were statistically insignificant between both the groups. Mean IMT and Plaque size reduction were more in group II. Conclusion: Both the therapies effectively improved the lipid profile in dyslipidemic patients. But combination therapy of Rosuvastatin with Ramipril reduces IMT and plaque size more than the rosuvastatin monotherapy. This shows that antiatherosclerotic action of combination therapy occurs due to its action on different risk factors of atherosclerosis.
\end{abstract}

Keywords: anti-atherosclerotic, Intimo-Media Thickness (IMT), plaque, statins, Angiotensin Converting Enzyme (ACE) inhibitor, Total Cholesterol (TC), Triglyceride (TG), Low Density Lipoprotein (LDL), High Density Lipoprotein (HDL), combination therapy

Cite This Article: Kumar Raj, Garg Ravinder, Aggarwal Simmi, Kohli Kamlesh, and Misra Gansham, "Comparative Study of Rosuvastatin as Monotherapy Versus Rosuvastatin with Ramipril in Dyslipidemia and Their Effects on Atherosclerosis.” American Journal of Medical Sciences and Medicine, vol. 2, no. 3 (2014): 5863. doi: 10.12691/ajmsm-2-3-2.

\section{Introduction}

Atherosclerosis is a major risk factor of the cardiovascular disorders. [1] It is one of the critical risk factors that influence the morbidity and mortality due to cardiovascular diseases in the worldwide. Cardiovascular diseases are directly linked to progressive atherosclerosis that has become the leading cause of mortality all over the world [2,3]. Every year about 17.3 million people die due to cardiovascular diseases, 7.3 million people die from coronary artery disease and 6.2 million from stroke each year [3]. It is projected that by the year 2030 there will be an increase in mortality upto 23.3 million due to cardiovascular diseases [3]. Its main causes are ageing, dyslipidemia, hypertension, diabetes, lipoprotein(a), homocysteine, smoking, alcohol, etc [1-5]. But dyslipidemia directly related to atherosclerotic process and enhances the deposition of the fats in the wall of arteries 
which can lead to narrowing of the lumen of the arteries and thus, obstructs the blood supply $[1,2,4]$. It can also lead to thrombo-embolic episode(s) which results in severe complications like stroke, transient ischaemic attack (TIA), ischemic heart disease, pulmonary embolism, etc $[6,7]$. It has been seen that patients with dyslipidemia have silent atherosclerotic disease i.e. increased intimomedia thickness (IMT) or plaque(s) of the arteries prior to the incidence of thrombo-embolic events $[6,7,8]$. If we can identify risk factors like dyslipidemia with increased IMT or silent plaques in the arteries at early stage $[6,7,8]$, then we would save the life of many patients from serious life threatening complications by taking appropriate steps. Statins (e.g. Rosuvastatin, Atorvastatin, etc.) are commonly used to treat dyslipidemia and also have pleiotropic actions (anti-atherogenic and antiinflammatory) $[9,10,11,12]$. While angiotensin converting enzyme (ACE) inhibitors (Ramipril, Enalapril etc.) are agents that inhibit conversion of angiotensin $I$ to angiotensin II (which is potent vasoconstrictor) and also has anti-atherosclerotic properties $[13,14]$. If we use both these agents at initial stages of atherosclerotic process, we can prevent the serious complications of cardiovascular diseases and thus, decrease the morbidity and mortality of many patients. This study was done to see the effect of Rosuvastatin as monotherapy and combination of Rosuvastatin with Ramipril on lipid profile and atherosclerosis (IMT and plaque) in carotid arteries in dyslipidemic patients and to evaluate the exact role of these agents in the treatment of atherosclerotic condition.

\section{Methods}

Flowchart -I (Study Design)

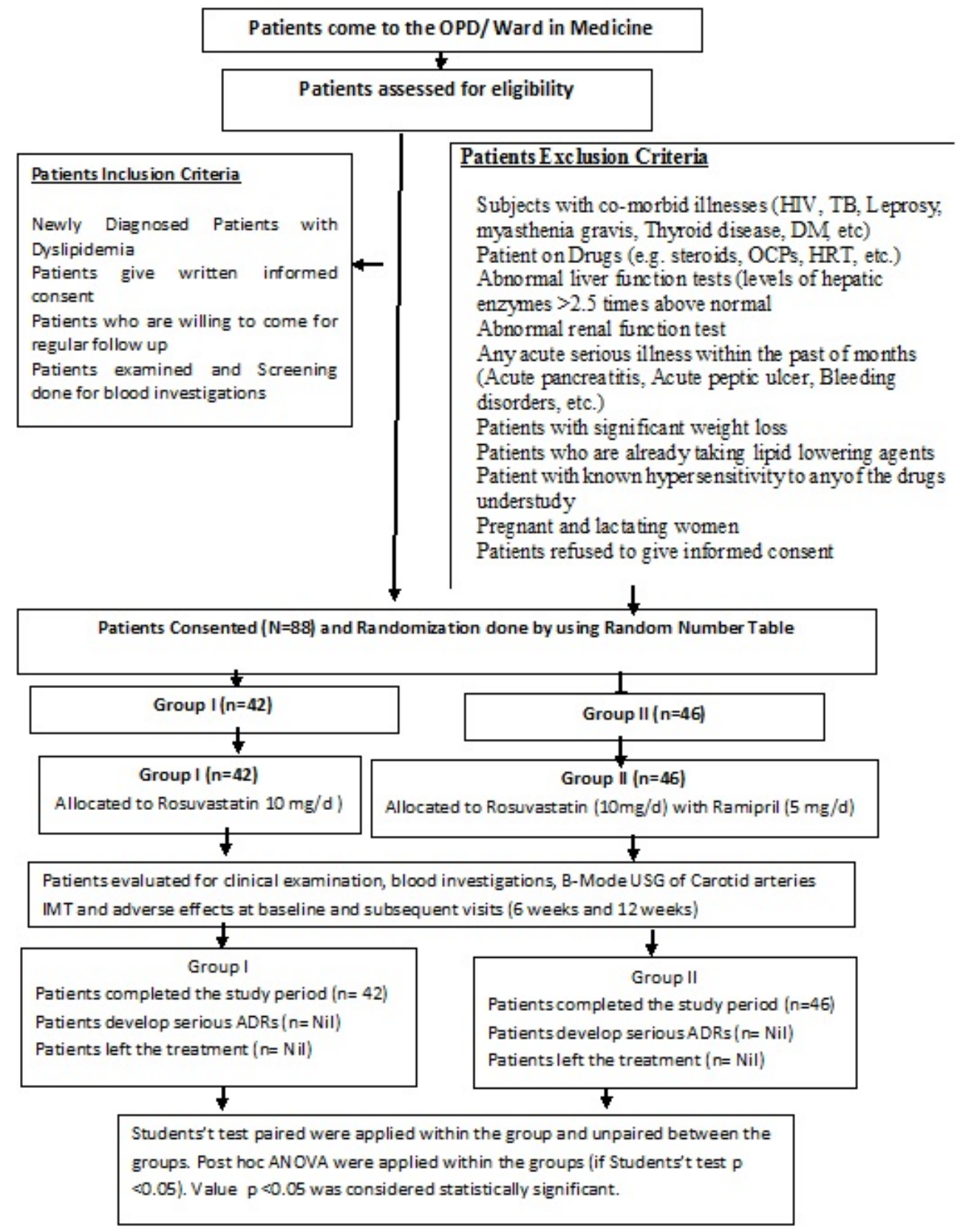

This was a randomized, open labelled, parallel study, conducted to assess the effects of Rosuvastatin as monotherapy (10 mg) and combination of Rosuvastatin
(10 mg) with ramipril (5 mg) daily for 12 weeks, 88 patients (42 in group I and 46 in group II) of newly diagnosed dyslipidemic patients, aged 30-70 years, were 
selected visiting the OPD/Wards of department of Medicine, Guru Gobind Singh Hospital attached to the Guru Gobind Singh Medical College, Faridkot, Punjab. The study drugs (monotherapy and combination therapy) were allocated among the patients randomly. The randomization was achieved by using a computer generated random number table. Patients were evaluated at day 0 , then at 6 and 12 weeks for clinical examination, lipid profile, Colour Doppler Ultrasonography of carotid arteries and other parameters (Flowchart-I). Subjects having dyslipidemia with or without hypertension or coronary artery disease (CAD) were enrolled. Subjects who were lactating, pregnant, hepatitis or cirrhosis of liver, bronchial asthma, HIV, tuberculosis, chronic inflammatory disease, thyroid disorders, diabetes mellitus, renal failure or patients on corticosteroids, oral contraceptive pills (OCPs), hormonal replacement therapy and patients who were sensitive to the study drugs were excluded from this study. All the Colour Doppler Ultrasonography measurements of CCA were performed by a single blinded expert reader. The Institutional Ethical Committee had approved the protocol of this study and all subjects were enrolled into the study after taking their written informed consent from them.

\subsection{Carotid Duplex Sonographic of Common Carotid Arteries}

Sonographic examinations were performed with Carotid duplex equipment of 7.5 MHz linear transducer (Phillips Envisor Company). Extracranial duplex investigations were including longitudinal and transverse examinations of carotid arteries. Patients were examined in supine position. IMT and other findings in the carotid arteries were measured during actual examination. IMT were measured at mid CCA (Common carotid artery) about $1 \mathrm{~cm}(10 \mathrm{~mm})$ proximal to common carotid bulb. IMT was measured between the leading edge of first echogenic line (Lumen Intima Interface) and second echogenic line (upper layer of adventitia) in the farwall and nearwall of the arterial wall [7]. For the IMT, mean value of three readings were took in the mid-segment of CCA.

A plaque is defined according to Touboul $\mathrm{P} \mathrm{J}$ et al. "as a focal structure that encroaches into the arterial lumen of at least $0.5 \mathrm{~mm}$ or $50 \%$ of the surroundings IMT value or demonstrates a thickness $>1.5 \mathrm{~mm}$ as measured from the media-adventitia interface to the Intima Lumen Interface. IMT of $<0.8 \mathrm{~mm}$ is normal while $>0.8 \mathrm{~mm}$ consider to be increased IMT thickness [7].

The primary endpoint of the study was change in the carotid IMT and secondary endpoint include changes in the serum lipid profile from baseline, mortality or morbidity. Safety parameters were also assessed for both the therapies.

\subsection{Statistical Analysis}

Data were expressed as mean and standard deviation (SD). Students't test applied between the groups and post hoc ANOVA within the group (if $\mathrm{p}<0.05$ within the group). Value of $\mathrm{p}<0.05$ is considered to be statistical significant.

\section{Results}

Baseline characteristics and baseline levels of different parameters of the group I and group II were compared at the start of therapies (Table 1 and Table 2). The difference in the parameters in both the groups was statistically insignificant (Table 3) at baseline.

Monotherapy with Rosuvastatin and combination therapy of Rosuvastatin with Ramipril in group I and group II showed significant $(<0.001)$ change of TC, TG, LDL and HDL level respectively at 6 weeks and 12 weeks (Table III) while no significant $(>0.05)$ change were seen in the IMT of carotid arteries and plaque size at the end of study.

Table 1. Baseline Characteristics

\begin{tabular}{|c|c|c|}
\hline Variables & Group I & Group II \\
\hline $\mathrm{n}$ & 42 & 46 \\
\hline Mean Age (years) (SD) & $56.12(9.731)$ & $54.65(9.185)$ \\
\hline $\begin{array}{c}\text { Gender } \\
\text { Male } \\
\text { Female }\end{array}$ & $\begin{array}{l}14 \\
26\end{array}$ & $\begin{array}{l}25 \\
11\end{array}$ \\
\hline Dyslipidemic & 13 & 4 \\
\hline Dyslipidemic with CAD & 10 & 4 \\
\hline Dyslipidemic with HT & 17 & 31 \\
\hline Dyslipidemic with CAD and HT & 2 & 7 \\
\hline
\end{tabular}

Table 2. Baseline Parameters values

\begin{tabular}{|c|c|c|c|}
\hline Parameters & $\begin{array}{l}\text { Group I }(\mathrm{n}=40) \text { Mean }(\mathrm{SD}) \\
\text { and } 90 \% \text { CI } \\
\end{array}$ & $\begin{array}{c}\text { Group II }(\mathrm{n}=40) \text { Mean (SD) } \\
\text { and } 90 \% \text { CI }\end{array}$ & $\begin{array}{c}\text { Students’t test (Unpaired) } \\
\text { p-value } \\
\end{array}$ \\
\hline Cholesterol (mg/dl) & 233.69 (47.5) 218.9-248.48 & 220.47 (54.82) 204.18-236.77 & $>0.05$ \\
\hline Triglycerides (mg/dl) & 245.66 (105.9) 212.66-278.67 & 237.36 (72.37) 215.86-258.88 & $>0.05$ \\
\hline LDL (mg/dl) & $\begin{array}{c}132.13(53.119) 115.58- \\
148.69 \\
\end{array}$ & 127.91 (46.26) 114.16-141.66 & $>0.05$ \\
\hline HDL (mg/dl) & 45.44 (5.50) 43.72-47.160 & 45.22 (6.42) 43.30-47.12 & $>0.05$ \\
\hline $\mathrm{SBP}(\mathrm{mmHg})$ & 137.28 (15.10) 135-140.72 & 149.56 (22.21) 142.96-156.17 & $>0.05$ \\
\hline DBP (mmHg) & 94.76 (9.43) 91.82-97.70 & 95 (13.45) 91-99 & $>0.05$ \\
\hline IMT of CCA Right (mm) & $\begin{array}{c}0.7938(0.1184) 0.7569- \\
0.8307\end{array}$ & $\begin{array}{c}0.7602(0.0723)(0.7387- \\
0.7817)\end{array}$ & $>0.05$ \\
\hline IMT of CCA Left (mm) & $0.829,(0.1925) 0.7692-0.8892$ & $0.7836(0.0846) 0.7586-0.8088$ & $>0.05$ \\
\hline IMT of ICA Right (mm) & 0.768 (0.0653) 0.7491-0.7879 & $\begin{array}{c}0.7422(0.07471) 0.7198- \\
0.7647 \\
\end{array}$ & $>0.05$ \\
\hline IMT of ICA Left (mm) & 0.8007 (0.157) 0.7516-0.8498 & $0.7761(0.104) 0.7452-0.807$ & $>0.05$ \\
\hline $\begin{array}{c}\text { Mean IMT (Four sites i.e Right and Left of both } \\
\text { CCA and ICA) }(\mathrm{mm})\end{array}$ & $\begin{array}{l}0.7934(0.1549) 0.7701- \\
0.8169\end{array}$ & $\begin{array}{l}0.7669(0.08694) 0.7543- \\
0.7795\end{array}$ & $>0.05$ \\
\hline $\begin{array}{l}\text { Average Plaque size in Carotid Arteries (Length X } \\
\text { Breadth) cm2 }\end{array}$ & $0.9684(2.701)-0.1995-2.136$ & 0.9136 (2.096) 0.2242-1.603 & $>0.05$ \\
\hline
\end{tabular}


Table 3. Mean Percentage Change in the Parameters at 6 weeks and 12 weeks

\begin{tabular}{|c|c|c|c|c|}
\hline & \multicolumn{2}{|c|}{ Group I } & \multicolumn{2}{|c|}{ Group II } \\
\hline Parameters & $\begin{array}{c}6 \text { weeks } \\
\text { Mean \%age change, } \\
\text { p-value and } \\
90 \% \text { CI }\end{array}$ & $\begin{array}{c}12 \text { weeks } \\
\text { Mean \%age change, } \\
\text { p-value and } \\
90 \% \text { CI }\end{array}$ & $\begin{array}{c}6 \text { weeks } \\
\text { Mean \%age } \\
\text { change, } \\
\text { p-value and } \\
90 \% \text { CI }\end{array}$ & $\begin{array}{c}12 \text { weeks } \\
\text { Mean \%age } \\
\text { change, } \\
\text { p-value and } \\
90 \% \text { CI }\end{array}$ \\
\hline T. Cholesterol & $\begin{array}{c}-15.88 \%, \mathrm{p}<0.001 \\
(184.89-208.59)\end{array}$ & $\begin{array}{c}-28.55 \%, \mathrm{p}<0.001 \\
(159.1-174.05)\end{array}$ & $\begin{array}{c}-18.2 \%, \mathrm{p}<0.001 \\
(171.42-189.27)\end{array}$ & $\begin{array}{c}-28.34 \%, \mathrm{p}<0.001 \\
(151.13-164.85)\end{array}$ \\
\hline TGs & $\begin{array}{c}-18.33 \%, \mathrm{p}<0.001 \\
(25.90-64.19)\end{array}$ & $\begin{array}{c}-33.37 \%, \mathrm{p}<0.001 \\
(63.14-101.43) \\
\end{array}$ & $\begin{array}{c}-21.67 \%,<0.001 \\
(33.04-62.49) \\
\end{array}$ & $\begin{array}{c}-33.74 \%, \mathrm{p}<0.001 \\
(59.661-89.112) \\
\end{array}$ \\
\hline LDL-C & $\begin{array}{c}-19.17 \%, \mathrm{p}<0.001 \\
(12.18-38.43)\end{array}$ & $\begin{array}{c}-35.59 \%, \mathrm{p}<0.001 \\
(33.84-60.10)\end{array}$ & $\begin{array}{c}-11.74 \%, \mathrm{p}<0.001 \\
(16.90-38.83)\end{array}$ & $\begin{array}{c}-21.10 \%, \mathrm{p}<0.001 \\
(39.13-61.05)\end{array}$ \\
\hline HDL-C & $\begin{array}{c}+6.51 \%, \mathrm{p}<0.001 \\
(46.623-50.187) \\
\end{array}$ & $\begin{array}{c}+13.23 \%, \mathrm{p}<0.001 \\
(49.658-53.246) \\
\end{array}$ & $\begin{array}{c}+7.83 \%, \mathrm{p}<0.001 \\
(47.139-50.383) \\
\end{array}$ & $\begin{array}{c}+16.66 \%, \mathrm{p}<0.001 \\
(51.057-54.421) \\
\end{array}$ \\
\hline SBP (mmHg) & $\begin{array}{c}-6.64 \%, \mathrm{p}<0.0001 \\
(119.65-125.50)\end{array}$ & $\begin{array}{l}-10.88 \%, \mathrm{p}<0.0001 \\
(114.30-120.04)\end{array}$ & $\begin{array}{c}-13.72 \%,<0.0001 \\
(124.52-131.04)\end{array}$ & $\begin{array}{c}-19.52 \%, \\
\mathrm{p}<0.0001 \\
(117.27-122.90) \\
\end{array}$ \\
\hline DBP (mmHg) & $\begin{array}{l}-5.56 \%, \mathrm{p}<0.0001 \\
(77.882-82.212)\end{array}$ & $\begin{array}{l}-11.41 \%, \mathrm{p}<0.0001 \\
(71.377-78.813)\end{array}$ & $\begin{array}{l}-9.88 \%, \mathrm{p}<0.0001 \\
(82.97-88.242)\end{array}$ & $\begin{array}{c}-17.25 \% \\
\mathrm{p}<0.0001 \\
(76.70-80.517) \\
\end{array}$ \\
\hline IMT of CCA Right (mm) & $\begin{array}{c}-0.05 \%, p>0.05 \\
(0.7565-0.8305)\end{array}$ & $\begin{array}{c}-0.05 \%, p>0.05 \\
(0.7565-0.8305)\end{array}$ & $\begin{array}{l}-0.026 \%, p>0.05 \\
(0.7386-0.7814) \\
\end{array}$ & $\begin{array}{c}-0.026 \%, \mathrm{p}>0.05 \\
(0.7385-0.7815)\end{array}$ \\
\hline IMT of CCA Left (mm) & $\begin{array}{c}-0.241 \%, \mathrm{p}>0.05 \\
(0.7680-0.8860) \\
\end{array}$ & $\begin{array}{c}-0.241 \%, \mathrm{p}>0.05 \\
(0.7680-0.8860) \\
\end{array}$ & $\begin{array}{c}-0.089 \%, p>0.05 \\
(0.7582-0.8074) \\
\end{array}$ & $\begin{array}{c}-0.14 \%, \mathrm{p}>0.05 \\
(07578-08072) \\
\end{array}$ \\
\hline IMT of ICA Right (mm) & $\begin{array}{l}-0.13 \%, p>0.05 \\
(0.7483-0.7874) \\
\end{array}$ & $\begin{array}{l}-0.13 \%, p>0.05 \\
(0.7483-0.7874) \\
\end{array}$ & $\begin{array}{c}-0.722 \%, \mathrm{p}>0.05 \\
(0.7198-7647) \\
\end{array}$ & $\begin{array}{c}-0.722 \%, \mathrm{p}>0.05 \\
(0.7202-0.7638)\end{array}$ \\
\hline IMT of ICA Left (mm) & $\begin{array}{c}-0.537 \%, \mathrm{p}>0.05 \\
(0.7505-0.8424)\end{array}$ & $\begin{array}{c}-0.537 \%, \mathrm{p}>0.05 \\
(0.7505-0.8424)\end{array}$ & $\begin{array}{l}-0.116 \%, \mathrm{p}>0.05 \\
(0.7447-0.8057)\end{array}$ & $\begin{array}{c}-0.116 \%, \mathrm{p}>0.05 \\
(0.7466-0.8082)\end{array}$ \\
\hline $\begin{array}{l}\text { Mean IMT (Four sites i.e Right and Left of both CCA and } \\
\text { ICA) (mm) }\end{array}$ & $\begin{array}{c}+0.01224 \%, \mathrm{p}>0.05 \\
\quad(0.7751-0.8170)\end{array}$ & $\begin{array}{c}+0.01224 \%, \mathrm{p}>0.05 \\
\quad(0.7751-0.8170)\end{array}$ & $\begin{array}{c}-0.01826 \%, \\
p>0.05 \\
(0.7543-0.7792) \\
\end{array}$ & $\begin{array}{c}-0.0704 \%, p>0.05 \\
(0.7539-0.7788)\end{array}$ \\
\hline $\begin{array}{l}\text { Average Plaque size in Carotid Arteries (Length X } \\
\text { Breadth) } \mathrm{cm}^{2}\end{array}$ & $\begin{array}{c}+0.115 \%, \mathrm{p}>0.05 \\
(-0.003662- \\
0.001001) \\
\end{array}$ & $\begin{array}{c}+0.006 \%, \mathrm{p}>0.05 \\
(-0.000754- \\
0.0006157) \\
\end{array}$ & $\begin{array}{l}-4.551 \%, \mathrm{p}>0.05 \\
(-0.06068-0.1566)\end{array}$ & $\begin{array}{l}-4.554 \%, p>0.05 \\
(-0.07102-0.1714)\end{array}$ \\
\hline
\end{tabular}

Both TC and LDL fall were less as reported by

\section{Discussion}

\subsection{Group I}

Rosuvastatin $10 \mathrm{mg}$ per day in group I resulted in statistically fall in serum TC, TG and LDL, at 6 weeks and 12 weeks (Table III). Both TC and LDL fall is less as revealed by CORALL study (33.2\% and $45.9 \%$, and $37.1 \%$ and $50.6 \%$ at both 6 weeks and 12 weeks respectively) [15] whereas fall in TC was more and LDL was less as observed by Yamazaki et al. (12.20\% and 22.94\% respectively) [11]. While TG level fall was more as revealed by CORALL study (23.7\%) [15] and Yamazaki et al (12.70\%) [11] at 12 weeks.

HDL level rises at 6 weeks was less as revealed by Jayram et al (13.8\%) ${ }^{16}$ while it was more as reported by Shepherd et al. (8\%) [17] and Yamazaki et al. (12.70\%) [11] at 12 weeks. SBP and DBP falls by $10.88 \%$ and $6.64 \%(\mathrm{p}<0.01$, both $)$ at 12 weeks.

Mean IMT value was slightly increased $(0.012 \%$, $\mathrm{p}>0.05$ ) (Table III) at 12 weeks from baseline, this was in contrast to as revealed by Nohara $\mathrm{J}$ et al. $(-1.36 \%, \mathrm{p}>0.05$, at 12 months) [9] Mok CC et al. $(-1.50 \%, \mathrm{p}>0.05$ at 24 months in SLE patients, mean IMT $0.68 \mathrm{~mm}$ at baseline) [12] and Crouse JR et al.(-0.057\%, $\mathrm{p}<0.001)$ [10].

Plaque size was increased by $3.15 \%(\mathrm{p}>0.05)$ at 12 weeks that it was the same as observed by Nohara $\mathrm{J}$ et al. (16.93\%, p >0.05 at 12 months) [9].

\subsection{Group II}

Combination therapy of Rosuvastatin (10 mg) with Ramipril (5 mg) per day resulted in statistically fall in levels of TC, TG and LDL at both 6 weeks and 12 weeks.
CORALL study while TG level fall was more as revealed by CORALL study [15] and Yamazaki et al. [11].

HDL level rises at 6 weeks was less as revealed by Jayram et al. while it was more than as observed by Shepherd et al. [17] and Yamazaki et al. [11] at 12 weeks.

SBP and DBP fall by $13.72 \%$ and $19.52 \%$ that were more as revealed by MacMohan et al. (5.26\% and 5.06\% respectively, with ramipril 5-10 mg/day) [18], Anderson K et al. (5.26\% and 5.06\% with ramipril 5-10 mg /day) [19] and Lonn et al. (4.52\% and $2.618 \%$ with ramipril 10 $\mathrm{mg} /$ day at 4 weeks) [14] but less as observed by Soni U et al. (25.40\% and $16.89 \%$ with ramipril $10 \mathrm{mg} /$ day at 12 weeks) [20].

Mean IMT value was decreased $(-0.0112 \%, \mathrm{p}>0.05)$ (Table III) and it was the less as revealed by Nohara J et al. ( $-1.32 \%, \mathrm{p}>0.05$ at 12 months) [9], Mok CC et al. (-1.50\%, $\mathrm{p}>0.05$ at 24 months in SLE patients, mean IMT $0.68 \mathrm{~mm}$ at baseline) [12] with monotherapy of Rosuvastatin while Mac Mohan et al [18] observed that IMT size was increased (+2.5\%, $\mathrm{p}>0.05$ ) with ramipril monotherapy for 48 months. Mean IMT was decreased in this study was same as observed in other studies (where monotherapy of either Ramipril or Rosuvastatin was prescribed) $[12,14,18]$ but these changes appeared after short duration of prescribing the combination therapy (at 12 weeks).

Plaque size reduction $(-4.08 \%, \mathrm{p}>0.05)$ (Table III) was same as revealed by Lonn et al. [(the mean maximum IMT $-37 \%$ (Relative Risk) with ramipril $10 \mathrm{mg} /$ day at the end of 2 years)] [14] while contrast finding was revealed by Mac Mohan et al. (+ 20.652\% with ramipril monotherapy at the end of 2 years) [18] and Nohara J et al. ( $+16.93 \%$, $\mathrm{p}>0.05$ ) [9] with rosuvastatin monotherapy (at 12 months).

\section{Comparison between group I and group II}


On comparing Rosuvastatin as monotherapy with combination therapy of Rosuvastatin with Ramipril, it was found that both the therapies equally improve the lipid profile at 6 and 12 weeks (Table III). However, both the therapies had not shown statistically significant difference on the IMT as well as plaque size at 6 weeks and 12 weeks respectively. But, there was decrease in mean percentage of mean IMT as seen in the combination therapy of Rosuvastatin with Ramipril as compared to Rosuvastatin group I. It was also observed that plaque size rose slightly in rosuvastatin group I while there was slight reduction in the plaque size with the combination therapy in group II.

Hence, the findings of reduction in the IMT and plaque size with combination therapy of Rosuvastatin with Ramipril, explained that synergistic effects were seen in combination therapy as compared to other studies where monotherapy of either Rosuvastatin or Ramipril was prescribed [12,14,18].

Studies have shown that there is increased tissue ACE (angiotensinogen converting enzyme) activity in atherosclerotic arteries and ACE inhibitors reduces atherosclerotic lesion area in these arteries due to their multitask actions viz. ACE inhibition, antiproliferative action as well as inhibitory to the smooth muscle cell accumulation at the site of atherosclerotic lesion. Ramipril is an ACE inhibitor agent that also has antiatherosclerotic, anti-inflammatory and anti-oxidative activity [13]. Whereas, Rosuvastatin improves the lipid profile by decrease the bad lipids (TC and LDL) and increases the HDL levels [11,12]. Therefore, synergistic action of both Rosuvastatin and Ramipril, acts against the atherosclerotic process which is helpful to treat the cardiovascular diseases at early stage, thus prevent the serious complications in these patients.

Both the therapies lead to mild side effects which were seen like GIT upset (4.7\% vs. 6.52\%), dizziness (2.38\% vs. $4.35 \%$ ) and dry cough (0\% vs. $2.17 \%$ ) in Rosuvastatin versus Rosuvastatin with Ramipril. Clinical examination and blood investigations of the patients had not shown any serious adverse events during the study period, thus indicated that both the therapies were well tolerated by the patients and also none of the patients were withdrawn during the study period.

Implication of the study: Combination therapy of statins with angiotensin converting enzyme inhibitors is useful to treat the atherosclerotic conditions in the cardiovascular diseases patients.

Limitations of the study were small sample size and short duration of the study. A double blind RCT with large sample size and longer duration is needed for the better analysis of the under study drugs.

\section{Conclusion}

Both the therapies effectively improved the lipid profile in dyslipidemic patients. But combination therapy of Rosuvastatin with Ramipril reduces IMT and plaque size more than the rosuvastatin monotherapy. This shows that antiatherosclerotic action of combination therapy occurs due to its action on different risk factors of atherosclerosis.

\section{Source of Support}

Nil.

\section{Conflict of Interest}

None Declared.

\section{References}

[1] Libby P. The Pathogenesis of Atherosclerosis. In: Kasper DL, Braunwald E, Fauci AS, Hauser SL, Longo DL, Jameson JL editors. Harrison's Principles of Internal Medicine. $16^{\text {th }}$ ed. New York: McGraw-Hill; 2005. p. 1425-1430.

[2] National Cholesterol Education Program (NCEP) Expert Panel on Detection, Evaluation, and Treatment of High Blood Cholesterol in Adults (Adult Treatment Panal III). Third Report of The National Cholesterol Education Program (NCEP) Expert Panel on detection, Evalution, and Treatment of High Blood Cholesterol in adults (Adult Treatment Panal III) final report. Circulation, 2002, 106, 3143-3421.

[3] World Health Organisation. Non-communicable diseases. Cardiovascular diseases (CVD). 2014; [1 Screen]. Available at: URL:http://:www.who.int/mediacentre/factsheets/fs317/en/\#. [Accessed May 10, 2014.

[4] Magyar MT, Paragh G, Katona E, Valikovics A, Seres I, Csiba Laszlo, et al., "Serum Cholesterol Have a More Important Role Than Triglycerides in Determining Intima- Media Thickness of the Common Carotid Artery in Subjects Younger Than 55 Years of Age”, J Ultrasound Med, 23, 1162-69, 2004.

[5] Herder M, Arntzen KA, Johnson SH, Mathiesen EB, "The metabolic syndrome and progression of carotid atherosclerosis over 13 years. The Tromso study", Cardiovascular Diabetology, 2012; $\quad$ 11: $\quad 77 . \quad$ Available at http://www.cardiab.com/content/11/1/77

[6] Valduza JM,Schreiber SJ, Roehl JZ, Klingebeil R. Neurosonology and Neuroimaging of stroke. Stugart:Ed.Theme.2008.

[7] Touboul PJ, Hennerici MG, Meirs S, Adams H, Amarenco, Bornstein P, et al. "Mannheim Carotid Intima-Media Thickness Consensus (2004-2006)", Cerebrovasc Dis, 23, 75-80, 2007.

[8] Lorenz MW, Markus HS, Bots ML, Rosvall M, Sitzer M, "Predication of clinical cardiovascular events with carotid intimamedia thickness: a systematic review and meta-analysis", Circulation, 115 (4), 459-67, 2007.

[9] Nohara R, Daida H, Hata M, Kaku K, Kawamori R, Kishimoto J, et al., "Effects of Long-Term Intensive Lipid Therapy With Rosuvastatin on Progression on Progression of Carotid IntmiaMedia Thickness”, Circulation Journal, 77, 1526-33, 2013.

[10] Crouse JR, Raichlan JS, Riley WA, Evans GW, Palmer MK, O'Leary DH et al., "Effect of Rosuvastatin on Progression of Carotid Intima-Media Thickness in Low-Risk Individuals With Subclinical Atherosclerosis-The METEOR Trial”, JAMA, 297 (12) 1344-52, 2007.

[11] Yamazaki D, Ishida M, Watanable H, Nobori K, Oguma Y, Terata $\mathrm{Y}$, "Comparison of anti-inflammatory effects and high- density lipoprotein cholesterol levels between therapy with quadrupledose rosuvastatin and rosuvastatin combined with ezetimibe", Lipids in Health and Disease, 12: 9, 2013. Available: http://lipidworld.com/content/12/1/9

[12] Mok CC, Wong KW, To CH, Lai JPS, Lam CS, "Effects of Rosuvastatin on Vascular Biomarkesr and Carotid Atherosclerosis in Lupus: A Randomized, Double-Blind, Placebo-Controlled Trial”, Arthritis Care and Research, 63 (6), 875-83, 2011.

[13] Munzel T, Keaney F, Are ACE Inhibitors a "Magic Bullet" Against Oxidative stress? Circulation, 104, 1571-74, 2001.

[14] Lonn EM, Yusuf S, Dzavik V, Smith S, Moore-Cox A, Riley WA, et al., "Effects of Ramipril, and Vitamin E on Atherosclerosis-The Study to evaluate Carotid Ultrasound Changes in Patients reated with Ramipril and Vitamin E (SECURE)”, Circulation, 103, 91925, 2001.

[15] Wolffenbuttel BHR, Franken AAM, Vincent HH, "Cholesterollowering effects of rosuvastatin compared with atorvastatin in patients with type 2 diabetes- CORALL study", Journal of Internal Medicine, 257, 531-539, 2005.

[16] Jayaram S, Jain MM, Naikawdi AA, Gawde A, Desai A, "Comparative Evaluation of the Efficacy, Safety and Tolerability 
of Rosuvastatin $10 \mathrm{mg}$ with Atorvastatin $10 \mathrm{mg}$ in Adult patients with hypercholesterolaemia: The First Indian Study”, Journal of The American Medical Association, 102, 48-52, 2004.

[17] Shepherd J, Packard C, Littlejohn Ill TW, Walker J, Stein EA, "Lipid-modifying effects of rosuvastatin in postmenopausal women with hypercholesterolemia who are receiving hormone replacement therapy”, Current Medical Research Opinion, 20 (10), 1571-1578, 2004.

[18] MacMohan S, Sharpe N, Gamble G, Clague A, Mhurchu CN, Clark T, et al., "Randomized, Placebo-Controlled Trial of the Angiotensin-Converting Enzyme Inhibitors, Ramipril, in Patients
With Coronary or Other Occlusive Arterial Disease”, Journal of The American College of Cardiology, 36 (2), 438-443, 2000.

[19] Andersen K, Weinberger MH, Egan B, Constance CM, Wright M, Lukashevich et al., "Comparative Efficacy of Aliskiren Monotherapy and Ramipril Monotherapy in Patients with stage 2 Systolic Hypertension: Subgroup Analysis of a Double-blind, Active Comparator Trial”, Cardiovascular Therapeutics, 28: 34449, 2010.

[20] Soni U, Moghe VV, Jain P, Upadhyaya P, “A Comparative Study of Efficacy and Tolerability of Telmisertan and Ramipril", International Journal of Pharma Sciences, 3 (3): 240-43, 2013. 